\title{
INVESTIGACIÓN/RESEARCH
}

\section{LOS EVENTOS EN EL ÁMBITO DE LA EMPRESA. HACIA UNA DEFINICIÓN Y CLASIFICACIÓN}

Gloria Campos García de Quevedo: Universidad Camilo José Cela. Madrid. España gloriacampos@protocolo.eu

Carlos Fuente Lafuente: Universidad Camilo José Cela. Madrid. España carlosfuente@protocolo.eu

\section{RESUMEN}

Este trabajo tiene por objeto el estudio de la organización de eventos en el contexto de las empresas españolas y en el sector profesional de la industria de los eventos, y la tipología y formato que adoptan los eventos en dicho ámbito para conseguir los objetivos para los que han sido promovidos y diseñados. La investigación profundiza a su vez, en el contexto en el que se desarrolla en España la industria de eventos en el marco de las empresas, su evolución y la identificación de los actores que la componen (empresas, proveedores, agencias de organización), todo ello, desde un enfoque comunicacional de la organización de eventos. Dado que el estudio académico de la organización de eventos en España es prácticamente inexistente, salvo el que lo vincula directamente al ámbito del protocolo, este trabajo indaga y analiza publicaciones académicas y científicas a nivel internacional, informes estadísticos para proponer una definición de evento en el ámbito de la empresa y sus características, y a partir de este análisis proponer una clasificación de los mismos. Para reforzar la propuesta realizada se han estudiado también las categorías y las características de los eventos que concurren a tres premios de gran prestigio de la industria de eventos en ámbitos de referencia para España, los European Best Event Awards (europeos), Festival Iberoamericano de Promociones y Eventos (Iberoamérica), y los Premios Eventoplus (España).

PALABRAS CLAVE: Comunicación - Empresas - Organizaciones - Acción comunicativa - Marketing.

\footnotetext{
${ }^{1}$ Autor correspondiente:

Gloria Campos García de Quevedo: Facultad de Comunicación de la Universidad Camilo José Cela. Madrid. España.
}

Correo: gloriacampos@protocolo.eu 


\title{
THE EVENTS IN THE SPHERE OF COMPANIES: TOWARDS A DEFINITION AND CLASSIFICATION
}

\begin{abstract}
The purpose of this paper is to study the organization of events in the context of Spanish companies, and in the professional sector of events industry, as well as the type and format adopted by these events to achieve the objectives for which they have been designed and promoted. The research focuses on the context in which the events industry develops in the world of Spanish companies, in its evolution, and identifying the different participants: companies, suppliers and events agencies; always from a communicational approach of event management. Considered the academic studies of the event management discipline as something almost nonexistent in Spain, except the one that links to protocol, this paper explores and analyzes different international academic and scientific publications, besides statistical reports, to propose a definition of corporate event and its characteristics, in order to facilitate a classification. As a support for the proposal of the research, this study has investigated the categories and the characteristics of those events that participate in three prestigious awards of the events industry in areas of reference for Spain: the European Best Event Awards (Europe), the Ibero American Promotions and Events Festival (Latin America), and Eventoplus Awards (Spain).
\end{abstract}

KEYWORDS: Communication - Companies - Organizations - Communicative actions Marketing.

\section{INTRODUCCIÓN}

Este trabajo tiene por objeto el estudio de la organización de eventos en el contexto de las empresas españolas y en el sector profesional de la industria de los eventos y la tipología y formato que adoptan los eventos en dicho ámbito para conseguir los objetivos para los que han sido promovidos y diseñados. La investigación profundiza a su vez, en el contexto en el que se desarrolla en España la industria de eventos en el marco de las empresas, su evolución y la identificación de los actores que la componen (empresas, proveedores, agencias de organización), todo ello, desde un enfoque comunicacional de la organización de eventos.

Para conseguir este objetivo se ha revisado la literatura académica al respecto y elaborado una propuesta de concepto de evento de empresa y su tipología desde la perspectiva de las Ciencias de la Comunicación. En este proceso se consideró necesario analizar en primer lugar el contexto organizativo de los eventos de empresa: la industria de eventos y sus actores (agencias, empresas, proveedores), a través del estudio de los informes estadísticos de instituciones oficiales, consultoras de comunicación y asociaciones del sector, publicaciones académicas, artículos de investigación, tesis doctorales y otro tipo de publicaciones. Se constató que la mayoría de dichas publicaciones se refieren a los aspectos operativos de los eventos, su 
proceso de planificación, organización y logística, la importancia económica, el turismo de reuniones y el impacto de los eventos culturales y deportivos; o bien, en el caso español, en su mayor parte, elaboradas desde la perspectiva del protocolo y el ceremonial, lo que ha obligado a repasar el marco conceptual del protocolo y su relación con los eventos en el ámbito de las empresas. Identificada la industria y sus actores, se analizó, en segundo lugar, qué es un evento empresarial, tipología y formatos.

En la indagación de las características de la industria de eventos se constató la importancia de los premios que otorgan los profesionales, empresas, agencias, proveedores y asociaciones para reconocer las cualidades de los mejores eventos que se realizan al año en todo el panorama nacional e internacional, y que constituye una importante referencia para esta industria. Dichos premios se convocan en diferentes categorías, normalmente similares entre los distintos galardones, lo que, desde el primer momento, ha verificado las tipologías estandarizadas de eventos catalogadas por la industria en todo el mundo. Dada la amplitud del tema y de las convocatorias

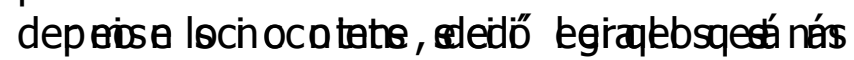

relacionados con la industria de eventos en España: los European Best Event Awards (europeos), el Festival Iberoamericano de Promociones y Eventos (Iberoamérica) y los Premios Eventoplus (España), todos ellos referenciados por los distintos actores de la industria como los de mayor prestigio y reconocimiento profesional.

\subsection{Interés científico.}

El estudio de la organización de los eventos empresariales en España es muy joven, las publicaciones académicas son escasas y las líneas de investigación relacionadas con dicha disciplina giran, principalmente, en torno al protocolo y el ceremonial y en los últimos cinco años, sobre la organización de eventos como herramienta de comunicación y marketing.

El enfoque comunicacional de la organización de actos es el más solido y fundamentado en el contexto académico e investigador, pero la propia naturaleza de la materia y su juventud en el ámbito de la investigación sugieren explorar otros enfoques y perspectivas, bien de forma independiente al enfoque comunicacional, o bien relacionándola.

Este trabajo profundiza en la conceptualización de términos que se utilizan en los estudios y publicaciones de organización y producción de eventos, algunos de ellos sin fundamentación teórica; otros, sin que haya acuerdo entre los distintos autores e investigadores estudiados y que aglutinan la mayor parte de producción bibliográfica y documental sobre el objeto de estudio de este trabajo.

La conceptualización de términos como evento y la clasificación de los mismos es necesaria para el marco teórico y científico en el que debe sustentarse la organización de eventos si aspira a ser parte de la ciencia. Por ello, es imprescindible introducirse en ese terreno. Junto a esto, se pretende contribuir a clarificar qué es el sector de 
eventos y qué incluye el concepto, porque difícilmente puede consensuarse una denominación del sector si no hay consenso sobre su propia definición.

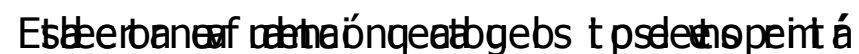

conocer algo más la relación entre cada uno de ellos y su objetivo comunicacional y con ello abrir nuevas líneas de investigación al respecto.

\section{METODOLOGÍA}

Este trabajo utiliza una combinación de métodos y técnicas que han ido aportando conocimientos y resultados. Wimmer y Dominick (1996) plantean que "el enfoque que

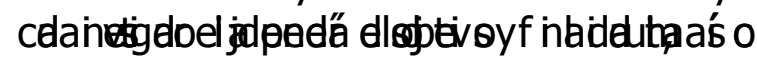
mo de los recursos necesarios" (p. 28).

\section{EŁane}

de la premisa de que el objeto de estudio de la misma era considerablemente nuevo o muy poco trabajado. Según Dance (1986), los estudios exploratorios en pocas ocasiones constituyen un fin en sí mismos, "por lo general determinan tendencias, identifican relaciones potenciales entre variables y establecen el tono de investigaciones posteriores más rigurosas" (p. 412). Se consideró una metodología lo suficientemente flexible en comparación con los estudios descriptivos o explicativos que, sin embargo, resultó no ser adecuada por la dispersión y falta de concreción de los resultados que se obtenían.

A partir de este proceso, se adoptó un diseño descriptivo centrado en caracterizar y sistematizar los eventos empresariales y su contextualización, especificando sus propiedades más relevantes. De esta forma, se identificó qué resultaba necesario medir, por qué y como, entendiendo que era necesario establecer la definición del concepto evento para llegar al evento empresarial y su tipología y realizar una muestra basada en el estudio de casos para identificar las características de los mismos y los elementos que intervienen en su capacidad, esto último objeto de otro artículo de investigación.

Tras la investigación documental, se recopilaron y procesaron los datos documentales de los eventos empresariales galardonados o finalistas en alguna de las categorías de los premios seleccionados como fuentes de la muestra. La selección se realizó consultando la documentación publicada (paginas web, revistas impresas, revistas electrónicas) de los eventos galardonados o finalistas en dicho marco temporal por el sector profesional del mercado de eventos y reuniones en nuestro país, en Europa y en Iberoamérica a través, respectivamente, de los Premios Evento plus, Premios Eubea (Europea Brest Evento Edwards) y Premios FIP (Festival Iberoamericano de Promociones \& Eventos). Con esta técnica se produce un acercamiento a la información que no fue documentada; es decir, estudiar aquello de lo que no hay nada escrito todavía.

Hay que señalar que entre las distintas fuentes de información que se utilizaron destacan la información y el material grafico obtenido de algunas revistas y boletines 
electrónicos especializados, principalmente, los editados y difundidos por el Grupo Eehops, áíc nopijadag nesogizdas apginavdebs

Premios Evento plus, FIP y Eubea, medios de comunicación generalistas y boletines digitales vinculados al sector de la organización de eventos. Entre estas fuentes mencionadas, todas ellas de marcado carácter de actualidad, publicaciones, informes y

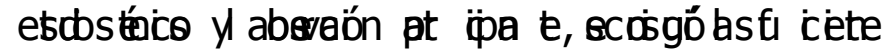

argumentación para construir el marco teórico objeto de esta investigación.

En la realización de este trabajo se constató la carencia de información que existe en cuanto a contenidos y características de los eventos empresariales y de las estrategias de comunicación que los promueven. Ello dificultó sobremanera la obtención de información, ya que el secretismo de los actores (agencias organizadoras, empresas y proveedores) de la industria de eventos ha exigido recurrir a información en Internet y a la experiencia profesional de los investigadores como organizadores de eventos. La inexistencia en España hasta el 2010 de estudios oficiales universitarios específicos en organización de eventos en nivel de grado y postgrado y la juventud de la industria no propició publicaciones científicas o líneas de investigación que incorporasen la significación de los eventos en alguna de las disciplinas de las distintas áreas del conocimiento científico. Por ello, se cuidaron sobremanera todas las referencias documentales y se diseñó la ficha de los casos estudiados para que pudiera servir de practican docente o de referencia para futuros investigadores.

\section{ANÁLISIS Y DISCUSIÓN}

Las fuentes académicas sobre la organización de eventos son todavía muy escasas en España. La implantación de estudios oficiales de grado y postgrado en las universidades españolas que contemplan en sus planes de estudio esta disciplina auguran un mejor futuro al respecto, ya que propiciaran sin duda la profundización en los trabajos que hay publicados y la apertura de nuevas líneas de investigación.

En general, la mayoría de los textos encontrados sobre organización y producción de eventos tienden, según Gales (2011), "a desarrollar desde el principio hasta el final la organización de un evento. Esto es lógico en un sector profesional y académico emergente y con un fuerte peso en la formación profesional" (p.8). Sí es cierto que gran parte de las publicaciones son practicas, y en términos generales se refieren a los aspectos operativos de los eventos, su proceso de planificación, organización y logística (Allen, O'Toole, McDonell, Harris, 2005; Bowdin, McDonnell, Allen, O'Toole, 2005 y 2010; Campbell, Robertson, Brown, S. y Race, R., 2003; Getz, 1990 y 2007; Golblatt, 2005; Masterman, 2004; Raj, Walters, Rashid, 2008; Robinson, Wale, y Dickson, 2010; Silvers, 2003; Tassiopoulus, 2005; Tum, Norton y Nevan, Van der Eagen, 2002; 2005; Watt, 1998), seguridad (Hannan, 1998; Ridley, 2008; Silvers, 2007; Tarlow, 2002), así como relativas a la importancia del turismo de reuniones y la industria del ocio en el crecimiento de los eventos en el mundo (Getz, 1991; Nicholson y Pearce, 2001; San Salvador, 2010), trabajos sobre la contribución de los eventos a la imagen de marca territorial (Aaker, 1994; Campillo, 2012; Baamonde, 2010, 2011, 2012; Baloglus y Mangaloglu, 2001; Fernández y Feijó, 2013; Jiménez y San Eugenio 2009; Costa, 2004; Dowling, 2001; Erickson y Kushner, 1999; Jiménez, 2005, Valls, 
1992), y a la historia de la ciudades (Baamonde, 2012; Batista, 2008; Benilis y Ordinas, 2003; Carrizo y Vieira, 2009; Espejo y Ponce, 1999; Vera, 1997).El estudio académico de la organización de eventos en España es prácticamente inexistente, salvo el que lo vincula directamente al ámbito del protocolo. De hecho, la formación universitaria en organización de eventos en nuestro país siempre estuvo ligada al protocolo, al ceremonial y a las relaciones institucionales, y normalmente integrada en los contenidos de diversas asignaturas contempladas en planes de estudios en el ámbito de las ciencias de la comunicación ${ }^{2}$.

Las publicaciones revisadas abordan principalmente temas relacionados con el impacto económico y las estrategias de marketing en los grandes eventos. Se observó un aumento de las investigaciones centradas en distintos aspectos de los eventos deportivos, principalmente, los relativos a los juegos olímpicos y a otras manifestaciones en el ámbito de la cultura y el ocio, así como en el turismo de reuniones.

Aunque las referencias son amplias, la realidad es que existen muy pocos trabajos sobre eventos que definan el marco conceptual de los eventos empresariales y que los analicen desde la perspectiva artística que plantea esta investigación. La juventud de la industria de eventos en España y la carencia de estudios específicos reglados en materia de organización de eventos hasta el año 2010 que dieron soporte a publicaciones o que propiciaran líneas de investigación al respecto, justifica el hecho de que en nuestro país el estudio de la organización de eventos empresariales desde la perspectiva científica sea prácticamente inexistente, salvo el que le vincula directamente al ámbito del protocolo.

De hecho, la formación universitaria en organización de eventos en España ha estado ligada al protocolo, al ceremonial y a las relaciones institucionales, y normalmente integrada en los contenidos de diversas asignaturas contempladas en planes de estudios en el ámbito de la ciencia de la comunicación. El primer contacto que tienen los estudios de Protocolo y Organización de Eventos con la universidad española se remonta al año académico 1997-1998, y lo fue de manera paralela con la Universidad Miguel Hernández de Elche y la Universidad de Granada (ambas públicas) para la implantación del Título Propio en Protocolo y Relaciones Institucionales, de 2.040 horas (204 créditos tradicionales) y una duración de tres años. En el año 2007, la

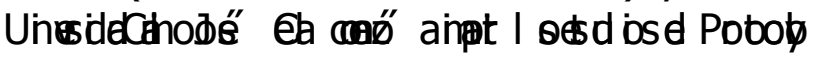

Relaciones Institucionales con una carga lectiva de 240 créditos tradicionales

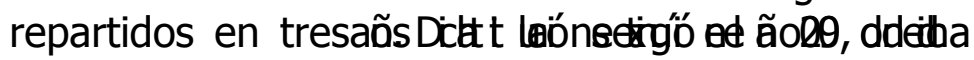

Universidad inició como titulación propia los estudios universitarios superiores en Organización de Eventos, Protocolo y Relaciones Institucionales con una carga equivalente a 240 ECTS repartidos en cuatro años académicos. En el 2010, la Agencia Nacional de Evaluación de la Calidad y Acreditación (ANECA) verifica el primer Grado Oficial en Protocolo y Organización de Eventos en España por la UCJC (BOE 07/01/2012) y en el 2011 hace lo mismo con el Grado en Organización de Eventos,

\footnotetext{
${ }^{2}$ Información extraída de la Memoria de Verificación del Grado Oficial en Protocolo y Organización de Eventos por la UCJC, verificada en septiembre de 2010.
} 
Protocolo y Relaciones Institucionales por la UMH (sin publicar en el BOE a la fecha de conclusión de este trabajo). Es también en el 2011 cuando la misma institución verifica el Máster Oficial en Dirección de Protocolo, Producción y Organización y Diseño de Eventos (BOE 09/07/2012). Según la Memoria de Verificación del Grado Oficial en Protocolo y Organización de Eventos por la UCJC, "en Europa y en distintos países del mundo sí existen estudios universitarios de Grado en Organización de Eventos. De hecho, su proliferación es muy amplia" (p. 9).

Si se relacionan los eventos con el protocolo y el ceremonial, existe mayor número de publicaciones y autores de referencia: Álvarez (2008, 2009); Arévalo (2001); Barquero (2004); Bosco (2003); Chivarro (2004); De Urbina (1989, 2001, 2004); Fernández, (2004); Fuente (2000, 2004, 2005, 2007, 2008); Hernández (2011); López Nieto (1985, 1995, 1998, 1999, 2000, 2003); Martínez (2006); Otero (1997, 2000, 2002, 2003, 2005, 2006, 2009); Pumar (2000, 2002); Ramos (2003, 2010); San Juan (2001); Sierra y Sotelo (2009); Tratan (1994); Bilirrubinas (1976, 1994, 2003, 2004), aunque gran parte de ellos lo abordan desde un punto de vista comunicacional. Por ello, se ha considerado pertinente, reseñar el concepto del protocolo y su relación con los eventos, para situar el contexto y marco teórico de los eventos de empresa en nuestro país, y en marco que contempla esta investigación.

La tipología y clasificación de eventos es otra de las discusiones habituales en la literatura académica; También se constata la escasa existencia en España de publicaciones que analicen o reverencien el nacimiento de la industria de eventos y de los eventos empresariales. Torrents, (2005) aborda de forma generalista la evolución de estos últimos en nuestro país y su capacidad de comunicación en vivo. Herrero (2011) y Campos (2010) ahondan en el poder de comunicación en vivo de los eventos. Bassat (2008) analiza los eventos desde la perspectiva de la comunicación de marca. Galmés (2011), en su tesis doctoral, aporta por primera vez desde la perspectiva científica un estudio sobre la evolución del sector en España y la clasificación de los eventos de comunicación de marketing (ECM). Ortega e Izaguirre, (eds.) (2010.), a través de una obra donde participan distintos autores, realizan una definición de eventos, situación y tendencias del sector, y características eventos especializados. Otero (2011) se adentra en los eventos de empresa y realiza una clasificación, pero más relacionada con el ámbito del protocolo y ceremonial. Junto a estos autores se han hallado distintos artículos científicos relacionados con los eventos y el turismo de reuniones.

Ante la ausencia de publicaciones específicas en esta materia, y como conclusión al análisis del estado de la cuestión de la organización de eventos, se consultaron también los estudios de mercado sobre la industria realizados por el Grupo Eventoplus en los años 2007, 2008, 2009, 2010 y 2012, los de la Asociación Meeting Professionals International (MPI en sus siglas en inglés), los anuales que realiza la Asociación Internacional de Congresos y Convenciones (ICCA en sus siglas en inglés), que elabora anualmente un informe estadístico que aúna los principales datos del sector del turismo de reuniones en todo el mundo, los informes estadísticos del mercado de reuniones que ofrece el Spain Convention Bureau y la Federación Española de Municipios y Provincias, los informes relacionados con el sector de eventos y la 
comunicación publicados por la Asociación Española de Directores de Comunicación (DirCom), las guías de recursos académicos de la Asociatión for Events Managament Education (AEME) y los informes que emiten los promotores de las ferias más importantes del sector: EIBTM (Barcelona), IMEX (Frankfurt), Heavent Expo (París).

Se ha visto necesario analizar estas fuentes bibliográficas para determinar el marco teórico de esta investigación y relacionarlas con el análisis de las mismas y otras documentales de los eventos en la empresa.

\subsection{Concepto de protocolo.}

El concepto de protocolo ha ido evolucionando en los últimos años desde una perspectiva más clásica, entendida bien como el ceremonial y las reglas de ordenación y ciertas pautas de comportamiento o exclusivamente como una técnica al servicio del marketing o de la comunicación -pero auxiliar o secundaria, en todo caso-, hasta el punto de adquirir un planteamiento más complejo, convirtiéndose en eje, en muchas ocasiones, de las estrategias de comunicación diseñadas por empresas o instituciones.

Según Campos (2008) "el protocolo actual hay que entenderlo desde un prisma más actualizado en el que reglas y normas conviven con nuevas disciplinas y con técnicas de organización enriquecidas con una visión más multidisciplinar" (p.24). Para Fuente (2007):

Aparece en los tiempos que corren el ya denominado protocolo integral o transversal, que precisa contemplar además de las técnicas tradicionales y las normativas, otras áreas de conocimiento como la comunicación, las relaciones públicas, el marketing, la publicidad, la creatividad, las nuevas tecnologías, las aplicaciones multimedia, la escenografía y el arte en general, el diseño, el interiorismo, la imagen, la economía y la comercialización, la gastronomía, la realización, la producción en general, habilidades directivas y así podríamos seguir con una larga lista de cuestiones que afectan a la gestión de los eventos (pp. 17-18).

Este mismo autor realiza esta reflexión cuando nos explica que las instituciones públicas y entidades privadas demandan "un perfil del organizador acorde con los tiempos" $y$, por ello, "exigen esta transversalidad porque los promotores de actos quieren rentabilizar al cien por cien sus inversiones en los mismos y llegar a sus públicos con claridad, convirtiendo sus eventos en momentos promocionales y de proyección de imagen" (Fuente, 207, pp. 17-18).

La gestión integral de un acto, según Fuente (2007), "ha hecho que el tradicional triángulo de la organización se nos antoje ya algo del pasado"(p.17). La producción, la creatividad y las tecnologías son elementos que se han sumado a la visión primigenia de la organización de actos que antes se sostenía sobre el protocolo, la seguridad y la comunicación. Por otra parte, y según Campos y Herrera (2010), "la Responsabilidad Social Corporativa (RSC) de las empresas encuentra en el protocolo moderno una herramienta para visualizar su actividad en la sociedad en la que se desenvuelve" (p.8). Pero las acciones de comunicación no se desarrollan solo hacia fuera para 
afianzar su reputación y conseguir captar el interés de los medios, sino también hacia el interior en un intento de afianzar la filosofía de la organización. El protocolo se convierte así en un elemento indispensable para la comunicación externa e interna. Como indica Martí (2008):

Si las instituciones o las grandes corporaciones desean mantener el protocolo más como imagen de la organización que como espacio de comunicación y participación con sus públicos pueden perder información para hacer más eficaz el acto de protocolo y conocer las vías de su mejora y desarrollo. (p. 19).

El protocolo está considerado en las publicaciones científicas editadas en España en los últimos doce años como una importante herramienta de comunicación estratégica, aunque todavía exista una gran discrepancia e incluso contradicciones entre los especialistas que han teorizado sobre su significado a partir de la segunda mitad del siglo XX.

La evolución del concepto ha sido vertiginosa en los últimos años. Otero (1999) llega incluso a establecer en las conclusiones de su tesis doctoral diferentes escuelas según el tipo de definición. Así, habla de:

La escuela tradicional diplomática (poniendo como referentes a Seres, Bandolín, Urbina, Tristán), el derecho (Francisco López-Nieto, Camilo López), la historia (Joaquín Martínez-Correcher, Felio A. Vilarrubias, Mauricio Domínguez Domínguez-Adame), la antropología (Miguel Ángel Radic) y la comunicación (José Pumar, José Pablo Arévalo García-Galán, Jorge Blanco Villalta, Noguero, Carlos Fuente, Juan José Laforet o Francisco Marín Calahorro). (Otero, 199 en Campos y Herrero, 2011, p. 8).

Otras tesis doctorales españolas sobre protocolo, en concreto las de Hernández (2006), Sierra (2007), Martínez (2008) y Álvarez (2008) insisten en la extensión a otros campos de la definición de protocolo, su relación con otras disciplinas transversales y su clara vinculación a la comunicación.

En definitiva, un concepto donde la organización está al servicio de unos objetivos, de la finalidad del acto y de los mensajes que se pretenden transmitir. Un protocolo que flexibiliza las precedencias y las normativas vigentes, así como los usos y costumbres tradicionales, y que valora singularmente la comunicación.

Fuente (2007) insiste en la idea de que la gestión integral de un acto, que conlleva ocuparse de otros factores adicionales de la organización, tales como la producción, la creatividad o el equilibrio presupuestario (por no señalar otros aspectos relacionados con otras disciplinas próximas como el marketing comercial, político o institucional) "ha hecho que el tradicional triángulo de la organización se nos antoje ya algo del pasado" (p. 28). El triángulo inicial que postulaba este autor a finales de los año 1990 da paso a una nueva teoría del protocolo, la teoría de la diana, en cuyos círculos concéntricos se sitúan la creatividad, la comunicación, el protocolo, la producción y la seguridad, y que lo más importante es:

Tener una buena idea del acto considerando los objetivos y la comunicación (a quién se quiere transmitir), programarlo correctamente (el protocolo), darle la 
forma adecuada (la producción), salvar las barreras y establecer las garantías de protección integral de las personas (la seguridad) y gestionar adecuadamente el dinero (el presupuesto) (Fuente, 2007, p. 23).

Otros autores señalan también la importancia de la producción, la creatividad, las tecnologías, la seguridad y, por supuesto, la comunicación. José Pumar (1995), vincula el Protocolo de Estado como emisor de comunicación: "El protocolo debe ser fiel reflejo del orden que debe presidir todo acto para que dé una imagen de prestigio de la propia corporación". Marín (2000) va más allá al afirmar que el protocolo es un instrumento que ordena los actos y forma parte de las estrategias y tácticas de la comunicación institucional, así como de la corporativa y de las organizaciones.

Existe un notable consenso entre los autores consultados al establecer que el protocolo es un conjunto de normas, tradiciones y técnicas mediante las cuales se regulan y planifican los actos promovidos por las instituciones públicas, entidades privadas y por las personas, se establece su orden y desarrollo, y se ordenan los invitados y los símbolos. Además, como indica Fuente (2008), es la "profesión que se ocupa de la organización de actos que afectan a las instituciones, entidades y personas, de la aplicación de las normas y tradiciones vigentes en este campo y de su ceremonial" (p. 51).

Del análisis realizado sobre estas definiciones y del contexto del que se desarrollan se ha llegado a la conclusión de cierta falta de disenso sobre cuál es la función real del protocolo en el ámbito de las instituciones y de la empresa, si es un concepto más relacionado con el ceremonial y las reglas que lo regulan o, como opinan los autores que defienden la óptica comunicacional, las técnicas que se utilizan para la organización de eventos, y una disciplina de suma importancia en las relaciones institucionales; o por el contrario, como opina Otero (2011), que analiza el término desde la perspectiva de las relaciones públicas, "no podemos seguir usando protocolo como sinónimo de organización de actos o eventos, puesto que el uno es una técnica de gestión de públicos y el otro una estrategia de relaciones públicas corporativas" (p.25). Marín (2004a, 2004b), que junto a Fuente (2007, 2008, 2009, 2010, 2011, 2013) es claro referente de la perspectiva comunicacional del protocolo, considera que este "se ha integrado dentro del marco actual de la comunicación global como un instrumento más de los que se utilizan para la proyección de la imagen pública de las instituciones y organizaciones" (p.9).

Se puede llegar a la deducción, por los textos de los autores citados, de que existe cierta pugna por situar el protocolo bajo el paraguas de una disciplina consolidada dentro de las Ciencias de la Comunicación, principalmente las Relaciones Públicas o como disciplina propia. La llegada a la universidad española de los estudios de grado y postgrado en protocolo y organización de eventos, no ha apaciguado el encendido debate entre los autores y evidencia la necesidad de crear un corpus teórico que sitúe el contexto académico en el que debe desenvolverse la organización de actos o de eventos y su consecuente perfil profesional. 
Este panorama nos lleva a una de las partes centrales de este trabajo de investigación: ¿qué son los eventos? ¿Y los eventos empresariales? ¿Qué papel ocupan en las organizaciones empresariales?

\subsection{Concepto de Evento.}

Se ha encontrado una mayor dificultad si cabe, en la definición en España, de los términos acto y evento, de sus diferencias o similitudes, siendo mayoritario cierto paralelismo entre estas palabras que con frecuencia se emplean para dar una mayor extensión al concepto de protocolo. En este sentido, Fuente (2005) afirma que:

Hoy entendemos como acto o evento (expresión que autoriza actualmente la RAE) el desarrollo de una función o representación destinada a cumplir los objetivos por los que se promueve y que se dota del ceremonial adecuado. Consta habitualmente de cuatro partes: un inicio o bienvenida, un desarrollo del objetivo central del mismo, un encuentro de carácter social y una despedida ( $p$. 54).

Sin embargo, el mismo autor considera que:

Esta disociación de actos y eventos según su promotor, ya no tiene sentido, al menos en la España actual, donde ha florecido una importante industria de eventos, reconocida como tal desde la década de los ochenta, en la que entran actos promovidos por las instituciones públicas, como el Día de las Fuerzas Armadas, Día de la Fiesta Nacional, inauguración de la Exposición Internacional de Zaragoza o la Exposición Universal de Sevilla, conmemoraciones milenarias de ciudades, y un largo etcétera de actos o eventos cuya gestión asumen empresas o agencias que se denominan de Comunicación o de Eventos (Fuente, 2012, p.120).

Otero (2011) se refiere de forma indistinta a estos términos para expresar lo mismo. De hecho, en sus publicaciones es frecuente que alterne las palabras acto o evento para referirse al acontecimiento. Marín (2004), desde la misma óptica de protocolo, relaciona el acto con un acontecimiento público y también los considera sinónimos en sí mismos. Indica que acto público "es aquel acontecimiento o evento que una organización celebra para informar de cualquier tema a sus diversos públicos" (p. 20). Y al definir evento, remite al término acto público (p. 86).

La palabra evento proviene del latín eventus y según el diccionario de la Real Academia Española (2001, 22a ed.) significa:

1. Acaecimiento, es decir "una cosa que sucede".

2. Eventualidad, hecho imprevisto o que puede acaecer.

3. Cuba, El Salv., Méx., Perú, Ur. y Ven. Suceso importante y programado, de índole social, académica, artística o deportiva.

En el primer caso se refiere a una actividad que va a suceder o sucede con seguridad, lo que elimina la eventualidad (segunda acepción), aunque ninguna de estas definiciones especifica o aclara a qué tipo de actividad o acontecimiento nos referimos. 
Sí lo hace la tercera acepción, donde se introduce la tipología de actividad a la que refiere un evento, pero circunscribiéndola a países hispanoamericanos.

El aspecto relacional que caracteriza a un evento no se ve recogido en ninguna de las definiciones que nos aporta la RAE. Es precisamente este aspecto el que hace del evento una herramienta estratégica de comunicación, ya que acerca la marca, la empresa a su público, interrelacionándolos e interactuando entre sí.

Para Galmés (2011) "es sorprendente la dificultad existente a la hora de aceptar términos y definir conceptos en este campo. El problema reside en que los eventos se trasladan a todos los ámbitos de la sociedad y a través de todo tipo de organizaciones" (p. 20). Y aclara que además "los estudios sobre eventos se acercan al término desde diferentes contextos, de forma que cada definición explica la actividad de los eventos desde una perspectiva concreta. Por ello, es prácticamente imposible dar una definición general y descontextualizada del término" (Galmes, 2011, p. 20).

Tampoco hay consenso respecto al término en el ámbito profesional, tal y como se desprende de revistas profesionales, estudios de mercado e informes estadísticos. Es frecuente leer en dichas publicaciones cómo una empresa concibe un evento y cómo la interpretación que realiza la agencia nada tienen que ver; pero, lo que es peor, que se desconozca por qué hay que realizar el evento, cuál es su motivación y su objetivo.

Autores como Baus y Lesly, 1981; Campos, 2009; Dayan y Katz, 1995; Fuente, 2007; Fuente, J. L., y Pérez Herrero, 2010; Lloyd, 1993; Marín, 1997; Noguero I Grau, 1988; Piñuel, 1997; Otero, 2000, 2004, 2005, 2009; 2011 y Stella, 1997, han definido el concepto de evento desde distintas perspectivas de la comunicación, el marketing, las relaciones públicas, el ceremonial y el protocolo. Para Bowdin, "el campo de aplicación de los eventos es actualmente tan amplio que hace prácticamente imposible encontrar una definición que incluya todas las variedades y formas de los eventos". (Bowdin en Berridge, 2007, p. 5). Esto afianza la idea de la interdisciplinaridad en la que se mueve la organización de eventos.

Getz (1990) y Goldblatt (1990) definieron los eventos como acontecimientos especiales, de una sola vez (carácter efímero), únicos y fuera de la marcha cotidiana de las empresas y/o instituciones. En el mismo sentido se pronunciaba años antes Arnaldi (1968), que acuña la expresión "acontecimientos especiales" para referirse a las iniciativas, sucesos $\mathrm{y} / \mathrm{o}$ hechos de distinta índole y naturaleza, de presencia pública, promovidos $\mathrm{y} / \mathrm{o}$ realizados por organizaciones fuera de su dinámica habitual para conseguir distintos objetivos. El concepto de acontecimiento no habitual que señalan estos autores y su cualidad de provisionalidad y momento único fuera de la rutina habitual ha sido aceptado por el mundo académico desde los distintos enfoques desde los que se aborda.

Para diferenciar un evento de la programación habitual en una empresa o institución, Getz (1991) define el evento especial como aquel que se celebra una vez de forma poco frecuente y fuera de la programación habitual de actividades. Para Ortega 
(2010), existe una tendencia actual a "denominar a los eventos con nombres únicos que distingan a ese evento, le confieran un carácter de singularidad o autenticidad $y$, por consiguiente, el ciudadano lo identifique claramente entre el resto de los eventos" (p. 14).

Wilkison (1998) señala que un evento especial "es un acontecimiento fuera de lo cotidiano diseñado para responder a unas necesidades específicas en un momento concreto". Añade que los eventos locales se pueden definir como "una actividad realizada para involucrar a la comunidad en una experiencia compartida en beneficio mutuo". (p. 20 en Galmés, 2011).

Ortega (2010) considera que "los organizadores de eventos utilizan la palabra evento para referirse a un acontecimiento programado que bien puede ser de índole cultural, de ocio o naturaleza profesional, sin discriminar necesariamente cuál es el grado de importancia" (p.14). Un evento puede ser desde una ceremonia de inauguración de unas olimpiadas a una pequeña exposición, inauguración o colocación de una primera piedra. Para Ortega (2010), existe una tendencia actual a "denominar a los eventos con nombres únicos que le distingan, que le confieran un carácter de singularidad o autenticidad $y$, por consiguiente, el ciudadano lo identifique claramente entre el resto de los eventos" (p. 14).

Baus y Lesly (1981, pp. 76-77) dan un paso más y aplican el paradigma de Lasswell (1948) a dichos acontecimientos especiales:

1. Qué: nombre del acontecimiento, alcance, preparación, presupuesto, elementos del programa.

2. Por qué: propósito y objetivo.

3. Cuándo: horarios y fechas.

4. Dónde: localidad geográfica, instalaciones.

5. Quién: empresa, institución u organización, invitado de honor, asistentes.

6. Cómo: forma de ejecución.

Carrera (1978) y Otero (2000) aplican a las relaciones públicas los elementos del modelo incorporando otros aspectos que lo enriquecen y actualizan. Golblatt (2005), que junto con Getz (1990) es autor de referencia dentro de la organización de eventos, reflexiona sobre la necesidad de delimitar el contexto de propio concepto y sobre si se debe partir de eventos especiales o de organización de eventos, decidiéndose por esta última opción, lo que se aparta de alguna forma del concepto que se intenta definir: el evento en sí mismo. Piñuel (1997) añade una reflexión de sumo interés para este trabajo: la visibilidad que aporta la puesta en escena de dichos acontecimientos y la interrelación entre los actores que ejecutan el acto (acontecimiento), quienes lo planifican y lo diseñan con el público al que se dirige, concediendo a la puesta en escena un gran valor estratégico para la consecución de los objetivos de comunicación.

A partir de todas las fuentes consultadas se plantea que el evento, por principio, es un acto en directo, efímero (irrepetible), relaciona en el mismo espacio al emisor y al 
receptor, va dirigido a un grupo específico de personas, es diseñado a medida y pretende generar una respuesta y actitud en su público. La capacidad para captar la atención de los invitados o públicos a los que va destinado (para comunicar experiencias mediante el acto en vivo, para hacer visible la marca y su aspecto relacional) hace que los eventos sean considerados una extraordinaria herramienta de comunicación y un canal perfecto para transmitir experiencias y fortalecer los mensajes que la empresa desea trasladar.

Está claro que el evento es un acontecimiento no habitual en el ámbito de las empresas y organizaciones que lo relaciona con su público para conseguir unos objetivos planteados dentro de las estrategias de comunicación de dichas organizaciones y para generar una respuesta o actitud en los públicos a los que va dirigido. Es por ello que el uso del vocablo evento se aproxima más al término en inglés event o en francés evénement, ambos referidos a acontecimiento, y que su significado está vinculado a los públicos a los que se dirige y con los que se interrelaciona. Como indica Goldbert (2005), hay que tener en cuenta a los stakeholders, las personas individuales o grupos que participan financiera, política 0 emocionalmente en un evento.

Para Galmes (2011), y desde esta perspectiva:

Los stakeholders pueden ser cualquier persona, empresa o grupo que tenga relación con el evento. Se consideran incluidos dentro del concepto stakeholders a organizadores, participantes, invitados, espectadores, trabajadores, proveedores de productos y servicios, empresas-clientes, clientes individuales, sponsors y medios de comunicación (p. 22).

Es evidente que este enfoque merece ser objeto de investigaciones futuras y de análisis de su adecuación a los acontecimientos que suceden en el ámbito de las instituciones públicas, organizaciones y empresas, así como finalidades, tipología y formatos y partes implicadas. Resulta de sumo interés para situar desde la perspectiva de la ciencia el poder comunicacional de estos acontecimientos que protagonizan un porcentaje significativo de los presupuestos y de las acciones representativas, promocionales o de posicionamiento de dichas organizaciones.

\subsection{Los eventos en el ámbito de la empresa. Clasificación y tipología.}

Las fuentes académicas sobre la organización de eventos son todavía muy escasas en España. La implantación de estudios oficiales de Grado y Postgrado en las universidades españolas que contemplan esta disciplina auguran un mejor futuro al respecto, ya que propiciarán sin duda la profundización en los trabajos que hay publicados y la apertura de nuevas líneas de investigación. 
En general, la mayoría de los textos encontrados sobre organización y producción de eventos tienden, según Galmes (2011), "a desarrollar desde el principio hasta el final la organización de un evento. Esto es lógico en un sector profesional y académico emergente y con un fuerte peso en la formación profesional" (p.8). Sí es cierto que gran parte de las publicaciones son prácticas y que en términos generales se refieren a los aspectos operativos de los eventos, su proceso de planificación, organización y logística (Allen et al., 2005; Bowdin, Getz et al., 2010; Campbell et al., 2005; Getz, 1990 y 2007; Golblatt, 2005; Masterman, 2004; Raj, Walters, Rashid, 2008; Robinson, Wale, y Dickson, 2010; Silvers, 2003 y 2004a, Van der Eagen, 2002 y 2004; Tassiopoulus, 2005; Tum et al., 2006; Watt, 1998), seguridad (Hannan, 1998; Ridley, 2008; Silvers, 2007; Tarlow, 2002), así como relativas a la importancia del turismo de reuniones y la industria del ocio en el crecimiento de los eventos en el mundo (Getz, 1991; Nicholson y Pearce, 2001; San Salvador, 2010).

Las publicaciones revisadas abordan principalmente temas relacionados con el impacto económico (Andersson, Persson, Sahlberg y Strom, (eds.) 1999) y las estrategias de marketing en los grandes eventos (Getz, 1999; Gnoth y Anwar, 2000; Goldblatt, 2007; Raltson y Hamilton, 1992; Ridley, 2008; Ritchie, 1984; Silvers, 2007). Se observa un aumento de las investigaciones centradas en distintos aspectos de los eventos deportivos (Hinch y Higham, (eds.), 2005; Masterman, 2004; Ritchie y Adair, (eds.) 2004;), principalmente los relativos a los juegos olímpicos (Bale y Christensen, (Eds.), 2004; Cashman, 2006; Cashman y Hughes, (eds.) 1999; Girginov y Parry, 2004; Roche, 2000), festivales de música (Crompton y McKay, 1997; Getz, 1999; Gnoth y Anwar, 2000; Hannan, 1998; Raltson y Hamilton, 1992; Ritchie, 1984; Yeoman, Robertson, Ali-Knight, Drummond, McMahon-Beattie, (eds.) 2003), y otras manifestaciones en el ámbito de la cultura y el ocio, así como en el turismo de reuniones (Getz, 2005; Hall, 1992; Van der Eagen, 2000 y 2002; Aeo, Beca y Eva, 2002).

Los siguientes autores analizan los marcos conceptuales para la comprensión y evaluación del impacto de los eventos (Kang, Perdue, 1994, Ritchie, 1984; Ritchie y Lyons, 1990; Ritchie, y Smith, 1991;), los eventos y su impacto en el turismo (Dimanche, 1996, Hiller, 1998, Carlsen, Getz, Soutar, 2000, Faulkner, Chalip, Brown, Jago, March, y Woodside, 2003; Getz, 2005) y la visión operativa de los mismos (Shone y Parry, 2004; Allen et al., 2005, Bowdin et al., 2006).

Aunque las referencias son amplias, la realidad es que existen muy pocos trabajos sobre eventos que contextualicen y definan el marco conceptual de los eventos de empresa, Torrents, (2005) aborda de forma generalista la evolución de los eventos de empresa en nuestro país y su capacidad de comunicación en vivo de los eventos. Herrero (2011) y Campos (2010) realizan estudios sobre la capacidad de comunicación de los eventos. Bassat (2008) aborda el tema desde la perspectiva de la comunicación de marca. Galmés, (2011), en su tesis doctoral, aporta por primera vez desde la perspectiva científica un estudio sobre la evolución del sector de eventos en España y la clasificación de los eventos de comunicación de marketing (ECM). Ortega e Izaguirre, (eds.) (2010.), a través de una obra donde participan distintos autores, realizan una definición de eventos, situación y tendencias del sector y características de eventos especializados. Junto a estos autores se han hallado distintos artículos 
científicos relacionados con los eventos y el turismo de reuniones. Sí existe más bibliografía sobre los eventos de empresa relacionada con el ámbito del protocolo y el ceremonial que con la comunicación en vivo.

\subsubsection{Definición de evento de empresa.}

Los eventos están considerados en el ámbito de la empresa como una parte importante de las estrategias de comunicación. La marca recurre al evento cuando tiene algo que comunicar. No se trata sólo de lanzar un mensaje a los públicos objetivos a los que se dirige. Se pretende algo más intangible: transmitir adecuadamente los valores de la marca y a la vez ser capaces de envolverlo en un entorno creativo capaz de transmitir emociones y experiencias únicas. Y, sobre todo, de trasladar el mensaje que se ha programado con los objeticos del evento. En algunos casos, estos son suscitar el interés de los medios e impactar en el público asistente; en otras ocasiones, fidelizar a los clientes. Según Herrero:

Hay que reconocer que un buen evento no sólo sirve para transmitir mensajes al público en general, sino puede segmentarse para llamar la atención de un grupo específico de personas, o incluso para transmitir a los mismos asistentes una serie de valores, pasando de la mera comunicación a la creación de emociones y sensaciones, otra forma de transmisión de los objeticos de un evento (Herrero, 2011, p.63).

Para Otero, los eventos corporativos, en alusión a los eventos empresariales, son:

Los organizados por todo tipo de organizaciones que no pertenecen al ámbito de los organismos oficiales. Pueden ser empresas, y generalmente los son, pero no podemos excluir a fundaciones, asociaciones ciudadanas, colegios profesionales, partidos políticos, clubes deportivos, iglesias, colegios y universidades privadas, sindicatos, confederaciones empresariales e infinidad de colectivos más (Otero, 2011, p. 61).

La misma autora indica que dichos eventos son "actos públicos no oficiales" (p.62) a los que considera genuinos eventos corporativos por ser "acontecimientos especiales organizados por empresas y demás organizaciones citadas" (p.62).

Torrents (2005), al considerar que los eventos de empresa son aquellos "actos en vivo organizados en función de los intereses comerciales o empresariales de una compañía o de una marca con el fin de trasladar un mensaje determinado a un público concreto para provocar una respuesta o generar una actitud" (p. 53), y añade:

Son actos en directo (en vivo), efímeros (irrepetibles, singulares), presenciales (emisor y receptor están físicamente en el mismo espacio), colectivos (dirigidos a un grupo de personas), diseñados a medida y que cuentan con una carga de motivación que pretende una respuesta determinada del público al que se dirigen. (Torrens, 2005, p. 34).

Para este autor, los eventos persiguen persuadir a un grupo humano y provocar una respuesta en la audiencia. Desde este punto de vista, los objetivos que persiguen son 
de motivación, corporativismo, "de sentimiento de pertenencia a un colectivo" (Torrents, 2005, p. 37), formación, notoriedad y recuerdo.

Para Palomares (en Revista Protocolo), gerente de Comunicación Comercial y Marketing Relacional de Telefónica España Grandes Empresas en 2011, "los eventos tienen un claro componente estratégico, ya que permiten generar espacios y momentos de encuentro de gran valor con los distintos stakeholders" (p. 8). Su convencimiento es tal que considera que tendríamos que realizarnos la siguiente pregunta: "¿Cuál sería el coste de dejar de hacer estas acciones?" (p. 8). Y continua: "Nuestra alta dirección está totalmente comprometida y decidida a seguir apostando por las acciones de comunicación, marketing y relaciones públicas. Cada año invertimos más en eventos" (p.8).

Desde su punto de vista, en la actualidad se consigue un mayor impacto con los buenos eventos por efecto de la crisis, refiriéndose al coste de organizar un evento como el de 48 horas con Telefónica. De ahí probablemente su creencia en la necesidad de conformar un buen equipo multidisciplinar en el departamento de eventos al margen de la dependencia a una u otra área. Para Palomares, los eventos

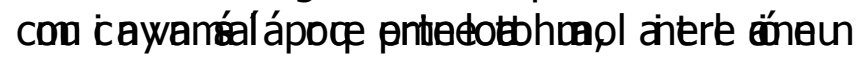

ambiente especialmente diseñado para ello. Según manifiesta:

Es absurdo. Las empresas nos jugamos mucho en los eventos. No sólo son un medio de relaciones públicas y/o institucionales, de fidelización y de imagen y reputación corporativa; constituyen un gran elemento diferencial de comunicación y dan valor a la empresa y las personas que la integran ( $p .8)$.

En este sentido, Herrero y Campos (2010), señalan que los eventos, además de comunicar,

Trasladan la imagen, estilo y responsabilidad social corporativa de una organización, permiten la interrelación con los stakeholders, parte fundamental de la planificación estratégica de la comunicación empresarial y generan experiencia, por lo que se convierten en herramienta estratégica en la comunicación en las organizaciones (p.3).

Sin embargo nada comunica por sí sólo: el evento debe estar dotado de contenido y forma para conseguir los objetivos corporativos. Es en este aspecto donde se ha observado un gran cambio, pasando de esquemas estándar (bienvenida, salutaciones, acto institucional, ágape o similar) a eventos con una gran creatividad en sus contenidos donde el diseño visual y plástico, la escenografía, los audiovisuales, las tecnologías multimedia y la irrupción del espectáculo escénico se convierten en auténticos transmisores de los mensajes corporativos.

Las compañías que comercializan productos y servicios necesitan posicionar o reforzar su marca y el evento puede ayudar bastante, pues relaciona la marca con sus públicos, humaniza ser parte de la esencia de la comunicación de dicha firma, ofrece visibilidad y personaliza su relación. 
Bassat $(2008)^{3}$, cuyo trabajo es referencia mundial de la comunicación de marca, considera que el evento "puede ser la esencia de la comunicación de una marca" (Bassat, 2008) y que es algo tan importante como puede ser un spot en la TV, una campaña de prensa o similar a través de Internet. "Para cada problema hay siempre una solución, y en muchos casos la solución a un problema determinado es un evento y no otra cosa"

Desde un enfoque similar, Galmés (2011) relaciona directamente los eventos en la empresa con el término Eventos de Comunicación de Marketing, ya que considera que este término describe mejor al evento como herramienta dentro de la Estrategia de Comunicación de Marketing (ECM), a los que define como:

Actos presenciales -organizados y planificados dentro de la estrategia de comunicación de marketing de una organización- con el fin de trasladar un mensaje sobre sus productos, marcas o sobre la propia organización, a un público objetivo, para provocar una respuesta, o para reforzar, crear o modificar una actitud, a partir de la experiencia del público (p. 27).

También desde la perspectiva del marketing, Mottard (2010) señala que los eventos son ante todo,

Una herramienta para comunicar un mensaje a un público muy selecto que, idealmente, repercutirá este mensaje o multiplicará su impacto: la prensa, los distribuidores, los comerciales, grandes clientes, líderes de opinión. Por eso, a pesar de su poder, apenas se oyen voces abogando por el todo evento: un evento es un componente de una campaña de comunicación. (Mottard en Ortega e Izaguirre (eds.), 2010, P. 67).

Partiendo de este enfoque y de la observación participante de eventos de los autores de este trabajo a lo largo de más de 35 años de experiencia profesional, se deduce que los eventos de empresa se convierten con frecuencia en un nuevo producto que hay que comunicar, porque materializan la marca a través de una experiencia que es vivida por un número de personas y comunicada a millones. Como ejemplo, podemos retrotraernos a la resaca del triunfo de España en la Eurocopa 2008, en la que muchas marcas vendieron a través de distintos formatos y estrategias su vinculación con la Eurocopa y con la selección española: coches, restaurantes, cervezas, marcas deportivas, refrescos, periódicos, bancos..., un sinfín de patrocinadores que mostraron su apoyo incondicional conscientes del valor mediático que genera un acto de tales dimensiones. Sin embargo, solo algunas compañías se fijaron en el alto valor emocional que suscita dicha competición. La cadena televisiva Cuatro desplegó una estrategia que tras el eslogan Podemos, ofrecía en cada partido de la selección española una experiencia que vinculaba las emociones y sentimientos de la competición a su cadena. La denominada plaza roja, la Plaza de Colón de Madrid, se convirtió en el espacio que la cadena televisiva ponía a disposición de los espectadores para vivir de forma conjunta cada partido. Para ello, creó un gran plató televisivo donde los comentaristas, presentadores, artistas y famosos conectaban con ese público que a través de pantallas gigantes y en directo vivían una jornada inolvidable.

\footnotetext{
${ }^{3}$ Entrevista realizada por el Grupo Eventoplus para Eventosmagazine, versión electrónica.

${ }^{4}$ Ibíd.
} 
Eran parte de una emoción que contagiaba al país y nos acercaba a la plaza roja a vivir la experiencia y a participar de forma indirecta en la pasión. Cuatro optó por un acto de experiencia, una acción que mira la calidad del impacto. De hecho, la maquinaria puesta en marcha por la cadena de televisión caló tanto en la población que cuando hubo que organizar un acto institucional para la celebración de la victoria española en el campeonato, las instituciones públicas y la propia Real Federación Española de Fútbol tuvieron que improvisar un nuevo escenario muy cercano al de la cadena, en la misma Plaza, para que se separara la parte oficial de la comercial, diferenciando así el origen de cada iniciativa, y para que se pudiera retransmitir a través de una señal institucional la victoria nacional manteniendo a la vez el público congregado, ya acostumbrado a visualizar y celebrar cada partido en la Plaza de Colón.

En este contexto, las marcas buscan medios que les permitan conectar con millones de personas y que causen un gran impacto $y$, además, distinto a esos miles de impactos que recibimos cada día a través de la publicidad. Como afirma Campos (2008):

El evento puede conseguir esta comunicación e impacto porque lo hace a través de múltiples canales y experiencias vivenciales, con los cinco sentidos, mediante audiovisuales, espacio, aromas, texturas, actividades, comida, decoración, música, etc. El evento permite captar la atención del público directamente y durante más tiempo que la publicidad, además de crear un marco para el contacto directo y la interrelación. La experiencia genera un recuerdo mucho mayor en su intensidad y más duradero que otros medios, lo que lo convierte en la actualidad en punto de mira y de interés de importantes marcas (p. 24).

Muchos tipos de eventos permiten captar la atención del público directamente y durante más tiempo que la publicidad, además de crear un marco para el contacto directo y la interrelación. La experiencia genera un recuerdo mucho mayor en su intensidad y más duradero que otros medios. De ahí que los eventos desde finales del S. XX, y a lo largo de la primera década del XXI conciten el interés de empresas y marcas. Ahora bien, todas estas bondades que le otorga el marketing se volverían en contra si el acto no estuviera bien diseñado, tanto en sus contenidos como en su forma, en su expresión escénica, técnica y artística.

De la revisión de las distintas definiciones analizadas se llega a la conclusión de que un evento de empresa es por principio es un acto en directo, efímero (irrepetible), relaciona en el mismo espacio al emisor y al receptor, va dirigido a un grupo específico de personas, está diseñados a medida y pretende generar una respuesta y actitud en su público. La capacidad para captar la atención de los invitados o públicos a los que va destinado para comunicar experiencias mediante el acto en vivo, para hacer visible la marca y su aspecto relacional hace que los eventos sean considerados como una extraordinaria herramienta de comunicación. Para que esto suceda, el evento debe cumplir los objetivos previstos: el mensaje debe llegar sin confusiones, con total claridad y el medio para trasladarlo debe ser coherente con lo que queremos comunicar y en cómo lo vamos a comunicar. 


\subsubsection{Clasificación y tipología.}

Definido el concepto de evento empresarial, es momento de indicar de forma muy somera la tipología de estos eventos, aunque ello no sea objeto concreto de este artículo. Es difícil realizar una clasificación concreta. No obstante, se detecta que los diversos autores que escriben sobre el tema tienden a fusionar la tipología de los eventos con formatos de eventos, generando cierta confusión, cuando el objetivo del evento es el que marca su tipología y el formato es el medio para conseguirlo. De esta forma, lo eventos de motivación pueden llevarse a cabo mediante viajes de incentivos, convenciones, networking, etc., o los de posicionamiento de marca mediante road show, happenings, acciones callejeras, de guerrilla, ambientales, promocionales, etc., o los institucionales mediante formatos clásicos como juntas de accionistas, eventos patrocinados, presentaciones, etc., los relacionales y co-participativos. Así se podría continuar desbrozando todas las modalidades de eventos que se observan en las acciones promovidas por la empresa.

Barridge (2007) revisa las distintas clasificaciones realizadas en el ámbito académico e indica que "para poder entender mejor los eventos es necesario los diferentes tipos de actividades y ocasiones que pueden considerarse eventos" (Barride, 2007, p. 11). Galmés (2011) indica que "la clasificación incluida en el proyecto EMBOK quizás sea la que más claridad pueda aportar al paisaje de los eventos en función de sus objetivos" (p. 31).

Tal como señala Galmés (en Ortega e Izaguirre (eds.), 2010 ), la lista sirve principalmente para clarificar:

Los campos de actividad en los que los eventos pueden estar presentes, y para entender mejor qué es un evento. Pero, hay que tener en cuenta que no es una clasificación en la que cada tipo de eventos excluya al otro, ya que en muchos casos, un evento concreto podría estar incluido en uno u otro apartado, o en dos a la vez. Entendemos que el objetivo de esta clasificación del Proyecto EMBOK no es excluir y delimitar, sino incluir y enumerar todos los posibles eventos (p.31).

Torrents (en Ortega e Izaguirre (eds.), 2010) considera que es difícil abordar una clasificación de eventos, ya que "es siempre una peligrosa simplificación" (p. 52). Y añade: "Las características que definen los eventos de empresa hacen de estos actos singulares, extraordinarios, irrepetibles, por lo que cualquier tipo de clasificación, aun siendo un recurso didáctico de utilidad, siempre será incompleta" (p. 53). Y clasifica los eventos en los siguientes tipos: convenciones de ventas, jornadas de puertas abiertas, actos protocolarios, inauguraciones, road show, aniversarios de empresa, viajes de incentivo y eventos especiales donde incluye todos los eventos no considerados anteriormente.

Mottard (en Ortega e Izaguirre (eds.), 2010) los clasifica en el mismo sentido, insistiendo en que son los eventos habituales que pueden encontrase en las empresas y que según el autor son: convención, viaje de incentivo, fiestas en la empresa, 
asistencia a ferias, participación en congresos, reuniones internas, ruedas de prensa, lanzamientos de producto y juntas de accionistas; e incorpora algo novedoso: los formatos que pueden darse en el contenido de dichos eventos, en función de sus objetivos, indicando que en respuesta a las nuevas prioridades de comunicación de las empresa, "nuevos formatos de eventos han salido en los últimos años aportando un nuevo abanico de opciones creativas de marcas" (Mottard, en e Izaguirre (eds.), 2010, p. 71), como pueden ser: la feria privada, el street marketing, tiendas efímeras, el evento cultural propio y la formación a clientes.

Vista esta clasificación, se considera que responde más a un catálogo de eventos habituales, con un cajón sin fondo donde pueden ir incorporándose todo tipo de eventos. Es correcto lo que aporta este autor en cuanto a la dificultad que existe para catalogar los eventos, ya que si se parte de la idea que cada uno de ellos es único y se diseña conforme a unos objetivos concretos para trasladar un o unos mensaje/s a su público, es difícil estandarizar categorías, porque puede realizarse en función de objetivos que nos llevaría a otra clasificación, de los mensajes, lo que requeriría un enfoque diferente, o en función de su contenido (Fuente, 2007), lo que vuelve a requerir otro enfoque distinto, o desde la perspectiva del marketing, donde los diferentes autores también se pronuncian: "Clasificar estos eventos es muy difícil debido a su gran diversidad y a la continua innovación y creatividad del sector" (Masterman y Wood 2006, p.221). Revisadas las publicaciones al respecto, se concluye que se prefiere una clasificación no cerrada y muy circunscrita a los eventos habituales que celebran las empresas.

Se han analizado las distintas categorías que se incluyen en los premios profesionales de la industria para eventos empresariales a nivel nacional (Premios Eventoplus, europeo (Premios Eubean) y en el ámbito Iberoamericano (Premios FIP) para comprobar si tienen relación con lo expuesto por los distintos autores. Al respecto, se identifican distintos tipos de eventos que coinciden en las categorías a los Premios Eventoplus, EuBEA y FIP, y son: Celebrity marketing (FIP); Congreso (Grupo Eventoplus, EuBEA; Convención (Grupo Eventoplus, EuBEA); Educational/Training Event (EuBEA); Evento cultural (Premios Eventoplus, EuBEA, FIP; Evento de celebración (Premios Eventoplus, EuBEA, FIP); Evento de motivación (Grupo Eventoplus, FIP); Evento deportivo (Premios Eventoplus, EuBEA, FIP; Evento incentivo (Premios Eventoplus, EuBEA; Evento promocional (Premios Eventoplus, EuBEA, FIP; Evento responsable (Grupo Eventoplus, EuBEA, FIP; Eventos infantiles (categoría incorporada en 2013, en los FIP; Evento presupuesto reducido (premio Eventoplus para 2013); Eventos solidarios (EuBEA); Feria (EuBEA); Green Event (EuBEA, FIP); Musical Events (EuBEA, FIP); Presentación/lanzamiento de producto (Premios Eventoplus, EuBEA, FIP); Eventos de lanzamiento de producto o marca interna o externamente; Road show (EuBEA); Strett Marketing (Unconventional Event) (EuBEA); Viaje de Incentivo/Team building (Grupo Eventoplus, EuBEA, FIP.

Como puede observarse, las categorías de estos prestigiosos premios, combinan el objetivo del evento: motivación, formación, responsabilidad social corporativa, etc.; contenidos: culturales, celebración, musicales, deportivos, sociales, infantiles, etc.; y 
formatos: convenciones, congresos, presentación productos, fiestas y celebraciones, eventos itinerantes, viajes incentivos, street marketing, ferias y de otro tipo.

También se premian componentes o elementos que determinan el éxito o fracaso del evento y otra serie de características:

- Mejor Decoración (Premios Eventoplus)

- Mejor Montaje Técnico (Premios Eventoplus)

- Mejor hotel/lugar (Premios Eventoplus)

- Mejor Aplicación de Catering (Premios Eventoplus)

- Mejor Nuevo Producto para Eventos (Premios Eventoplus

- Mejor animación o espectáculo (Premios Eventoplus

Los Best Event Awards también premian otra serie de características tales cómo:

- Mejor visión, refiriéndose a la mejor idea creativa.

- Mejor ejecución (mejor dirección, mejor diseño de ensayo / set ubicación / entorno, la mejor producción de iluminación audio / video).

- Mejor participación de los consumidores.

- Mejores resultados (estrategia de relaciones públicas, impacto medios de comunicación, entre otras cuestiones).

Innovación, calidad, adecuación al mensaje y a los objetivos son criterios a juzgar para la concesión de premios, dando gran importancia a los elementos artísticos, visuales, plásticos y audiovisuales de la puesta en escena en el resultado final del evento. Impactar y sorprender también se repite en los criterios que juzgan los jurados de estos premios.

Vista la opinión de los autores citados y las categorías de los premios que se analizan en este trabajo, los eventos pueden clasificarse de forma diferente en función de sus objetivos y a partir de ahí adoptar distintas formas con diferentes contenidos, como convenciones, presentación de productos, eventos itinerantes, de incentivos, de celebración (aniversarios, galas, fiestas...), de entrega de premios, de posicionamiento de marca, promocionales, culturales, deportivos, académicos, institucionales, sociales, de responsabilidad social corporativa, ambientales, etc.

En todos los casos son eventos que se vertebran sobre un eje comunicacional: qué se quiere conseguir y qué se quiere comunicar, y siempre están orientados hacia logros y resultados. Están programados con bastante antelación y contemplados normalmente en los presupuestos anuales de la empresa. Pueden diferenciarse en dos grandes bloques:

1. Eventos de proyección externa, dirigidos a un público ajeno a la empresa. Se caracterizan por una mayor superficialidad en los mensajes, ya que van dirigidos a un público muy heterogéneo. Su finalidad puede ser muy diversa: institucional, de posicionamiento, de motivación (de agentes externos), promocionales, formación, etc. 
2. Eventos internos, hacia dentro de la empresa, dirigido al personal de la misma o público vinculado de forma muy estrecha: principalmente eventos de formación, motivación e incentivo.

A su vez es necesario distinguir entre los contenidos sobre los que se construye un evento y el formato que se le da, es decir, la denominación del evento/acontecimiento, con independencia de los objetivos del mismo, pues en un mismo tipo de evento pueden combinarse distintos objetivos (formación, motivación, premiar, promocionar, etc.).

Atendiendo a su contenido, hay que hablar de la clasificación que realiza Carlos Fuente (2005, p. 86), que establece las siguientes categorías: Estado (no aplicable a eventos de empresa), institucionales, comerciales, culturales, religiosas, académicas, deportivas, sociales y familiares), aunque con matices, ya que recuerda que la distinción entre un acto promovido por una entidad empresarial de otro promovido por una institución viene establecida en el concepto de oficial y no oficial. También considera que "la tradicional separación de los actos en oficiales y de empresa es un error" (p.86), ya que si catalogamos estos últimos, también deberíamos hacer lo mismo con otras entidades que no siendo empresas, también son de naturaleza privada, como las federaciones, asociaciones, etc.

Pese a esta afirmación, se ha considerado que pueden identificarse los formatos de eventos más habituales en las empresas, y siempre desde la idea del evento como acontecimiento especial. Un evento puede a su vez combinar distintos formatos y contemplar diferentes actividades. La clasificación que se propone por tanto, se realiza atendiendo a los objetivos de los eventos, y dentro de ella se señalan los formatos de los mismos, es la siguiente:

- Eventos celebración: aniversario, conmemoración, fiesta, y eventos con formatos que respondan a objetivos de celebración.

- Eventos formación: conferencia, convenciones, reuniones y congresos, y aquellos otros cuyo objetivo principal es la formación, en el que pueden combinarse distintas actividades o formatos formativos o educacionales.

- Eventos motivación: convención y/o reuniones, donde se combinan a su vez otros objetivos como motivación, incentivos, presentación de productor, etc., y contemplan distintas actividades.

- Eventos de reconocimiento: entrega premio/s y/o reconocimiento/s.

- Eventos institucionales: inauguraciones, jornada puertas abierta, visitas instalaciones, eventos públicos.

- Eventos societarios: junta de accionistas, consejo administración, otros.

- Eventos comerciales y de lanzamiento/presentación de producto. Dentro de esta categoría pueden encuadrarse también las ferias bien las organizadas por la empresa, o bien la asistencia a las mismas.

- Eventos promocionales: persiguen la notoriedad de la marca y la fidelización. Podemos distinguir entre ellos: posicionamiento de marca; itinerantes: Road Show; Street Marketing; Samplings; Otros.

- Eventos protocolarios: marcados por la asistencia de personalidades del ámbito político, tanto de las instituciones del Estado, como del ámbito internacional. Estos 
eventos tienen como objetivo añadido el refrendo institucional que aportan las personalidades que asisten.

- Eventos de incentivo: viaje de incentivo o eventos basados en un formato que incentive a los participantes en el mismo.

- Eventos responsables/solidarios, en los que la política de responsabilidad corporativa de la empresa cobra gran peso e importancia en el diseño del mismo. Son eventos pensados para una mayor notoriedad de la empresa, marca y para trasladar el compromiso de la misma con la sociedad.

- Eventos Sostenibles/Green Events: eventos con claro objetivo de respeto y cuidado al medio ambiente, pueden adoptar cualquiera de los formatos que se incluyen en esta lista.

- Eventos culturales. Dentro de este apartado, se encuadrarían aquellos eventos de la industria del ocio y de la cultura. En los premios Eubean, prefieren distinguir el evento cultural, del evento musical.

- Eventos deportivos. Aquellos que se organizan para realizar una o varias actividades deportivas, o los que se relacionan con la competición o actividad deportiva, como puede ser la ceremonia de inauguración o clausura de unos juegos olímpicos.

- Eventos de patrocinio. Son aquellos que financian en su totalidad o en parte las empresas o las marcas concretas, aunque pueden adoptar distintos formatos, por ejemplo un festival de música patrocinado por una marca de cervezas.

- Otros eventos y formatos.

Cada uno de estos eventos combina distintos formatos que normalmente vienen determinados por las actividades que se organicen y que suelen ser:

- Actividades de teambuilding.

- Catering en sus distintos formatos.

- Actividades networking.

- Actividades de formación.

- Otras actividades

\section{CONCLUSIONES}

El evento de empresa es un acto en directo, efímero (es irrepetible), relaciona en el mismo espacio al emisor y al receptor, va dirigido a un grupo específico de personas, está diseñado a medida y pretende generar una respuesta en el público presente. Se diferencia de otros en que está motivado por la necesidad de trasladar un mensaje concreto a un público determinado y seleccionado o preseleccionado y en principio limitado. Su acción hace posible la visibilidad de la marca y además aporta el aspecto humano de la misma que permite la interrelación entre personas en un mismo espacio.

Concluimos que los eventos empresariales se vertebran sobre un eje comunicacional a través del cual se determina qué se quiere conseguir y qué se quiere comunicar demostrando que siempre están orientados hacia logros y resultados. Se ha determinado también que los eventos pueden clasificarse de forma diferente en función de sus objetivos y a partir de ahí adoptar distintas formas con diferentes 
contenidos, en todos los casos son eventos que se vertebran sobre un eje comunicacional: qué se quiere conseguir y qué se quiere comunicar, y siempre están orientados hacia logros y resultados. Están programados con bastante antelación y contemplados normalmente en los presupuestos anuales de la empresa. Pueden diferenciarse en dos grandes bloques: eventos de proyección externa y eventos internos.

En este artículo se ha propuesto una clasificación no cerrada de los eventos atendiendo a los objetivos de los mismos, y dentro de ella se señalan los formatos que pueden adoptar. En base a ello, se han identificado los siguientes tipos de eventos de empresa: de celebración; de formación; de motivación; de reconocimiento; institucionales; societarios; comerciales y de lanzamiento/presentación de producto; promocionales; protocolarios; de incentivo; responsables/solidarios; sostenibles/Green events; culturales; deportivos; de patrocinio.

Por otra parte hemos concluido que el objetivo del evento es el que marca su tipología y el formato es el medio para conseguirlo, así como que el contenido de la mayor parte de los eventos combinan distintos objetivos: motivación, formación, responsabilidad social corporativa, etc.; contenidos: culturales, celebración, musicales, deportivos, sociales, infantiles, etc.; y formatos: convenciones, congresos, presentación productos, fiestas y celebraciones, eventos itinerantes, viajes incentivos, street marketing, ferias, etc.

\section{BIBLIOGRAFÍA.}

Álvarez, M. L. (2008). Nociones de protocolo desde la bibliografía de sus autoridades. Tesis doctoral dirigida por Daniel Martí. Facultad de Ciencias Sociales y de la Comunicación. Universidad de Vigo.

(2008b). Nociones de protocolo desde la bibliografía de sus autoridades. Revista Latina de Comunicación Social, 63, 165-173.

Allen, J., O"Toole, B. McDonnell, I., Harris, R. (2005). Festival and Special Events Management. Australia: John Wiley \& Sons, Inc.

Andersson, T.D., Persson, C., Sahlberg, B. and Strom, L., (eds) (1999). The Impact of Mega Events. Ostersund: European Tourism Research Institute.

Arévalo, J. P. (2001). La Ciencia del Protocolo. Burgos: Ediciones Protocolo.

Arnaldi, P. (1968): Manual de Relaciones Públicas. Madrid: Ibérico-Europea de Ediciones.

AEO, BECA y EVA (2002). The Guide to Managing Health and Safety at Exhibitions and Events (The Red Book). Berkhamsted: Association of Exhibition Organisers, 
Bale, J. Y Christensens (eds.), (2004). Post-Olympism?: Questioning Sport in the Twenty-First Century (Global Sport Cultures).Chicago: Berg. ISBN 10: 1859737196 / ISBN 13: 9781859737194.

Barquero, J.D., Fernádez, F. (2004). El libro azul del protocolo y las relaciones públicas. Madrid: McGraw-Hill / Interamericana de España, S.A.

Barriga, A (2010). La creatividad en los eventos. Madrid: Ediciones Protocolo.

Bassat, L. 2008). El evento puede ser la esencia de la comunicación de una marca. Recuperado el 12 de junio de 2010 de: http://www.eventoplus.com/articulo/271/23/lluis-bassat-\%E2\%80\%9Celevento-puede-ser-la-esencia-de-la-comunicacion-de-una-marca\%E2\%80\%9D/ (2011). El libro rojo de la publicidad (11 Ed.). Barcelona: Mondadori.

Baus, H.M., y Lesly, P. (1981). Preparaciones para la comunicación, en Lesly, P. Nuevo Manual de Relaciones Públicas. Barcelona: Martínez Roca.

Berridge, G. (2007). Event Design and Experience. Oxford: Butterworth-Heinemann (Events Management Series).

Bosco, J. (2003): Imagen artística y ceremonial. Laurea Hispalis. Revista Internacional de Investigación en Relaciones Públicas, Ceremonial y Protocolo, (2), 23- 38.

Bowdin, G., McDonnell, I., Allen, J., O’Toole, W. (2010). Events Management (3a ed.). Oxford: Butterworth-Heinemann.

Campos, G. (2008). Producción de actos. La puesta en escena del protocolo. Madrid: Ediciones Protocolo.

(2011). Las artes escénicas, el espacio y su relación con los eventos. En Baraño, K y Escanero, P (Ed.), Support/Surface. Escultura y paisaje (pp. 228-258). Alicante: Fundación Cañada Blanch.

(2012). Protocolo para vender. En Misiego, F y Ortega, E (Coord.), Cómprame y iVende!. Las 20 píldoras de los maestros del marketing (pp. 83-88). Madrid: Rasche.

(2013, 21 de marzo). El mercado de eventos se mueve: del Show al Business (en línea). Blog de Gloria Campos, recuperado el 14 de abril de 2013 de: http://www.gloriacampos.com/2013/03/el-mercado-de-eventos-semueve-del-show_9867.html

Campos G y Herrera, J.C. (2010). El necesario protocolo en la comunicación organizacional. Icono14, no 16, recuperado el 5 de julio de 2010 de http://www.icono14.net/monografico/protocolo-en-la-comunicacionorganizacional. 8/2

Campbell, F.; Robertson, A.; Brown, S. y Race, R. (2003). Essential Tips for Organising Conferences and Events. Kogan Page. 
Carrera, F. (1978). Vigencia de los Modelos Aristotélicos en Teoríae Investigación de la Comunicación Persuasiva de Masas. Tesis doctoral sin publicar, Universidad Complutense de Madrid.

Cashman, R. (2003). 'What is Olympic legacy?', en M. de Moragas, C.Kennett and N. Puig, eds, The Legacy of the Olympic Games 1984-2000, Lausanne:

International Olympic Committee, 31-42.

(2005). The bitter-sweet awakening: the legacy of the Sydney 2000 Olympic Games,Sydney: Walla Walla Press.

(2006). The Bitter-sweet Awakening:The Legacy of the Sydney 2000 Olympic Games. Sydney: Walla Walla Press in conjunction with the Australian Centre for Olympic Studies, University of Technology.

Cashman, R. y Hughes, A. (eds.) (1998). Staging the Olympic: The Event and is Impact. Sydney: University of New South Wales Press.

Chávarri, T (2004). Protocolo Internacional. Madrid: Ediciones Protocolo.

Crompton, J.L. y McKay. S.L. (1997). Motives of visitors attending festival events. Annals of Tourism Research, 24 (2), 425-439.

Dayan, D. y Katz, E., (1992). Media Events: The live broadcasting of history. Harvar: Harvard University Press.

De Urbina, J. A. (1989). El arte de invitar: su protocolo. Madrid: Consejo Superior de Comunicación y Relaciones Públicas de España.

(2001). El Gran libro del protocolo. Madrid: Temas de Hoy.

(2004). 100 preguntas básicas de protocolo. Madrid: Temas de Hoy.

Dimanche, F., 1996. Special events legacy: The 1984 Louisiana World fair in New Orleans. Festival Management \& Event Tourism, 4(1), pp. 49-54.

Faulkner, B., Chalip, L., Brown, G., Jago, L. March, R., and Woodside, A., 2003. Monitoring the tourism impacts of the Sydney 2000 Olympics. Event Management, 6(4), pp. 231-246.

Fernández, F. (2004). Ceremonial y Protocolo: Guía Completa. Madrid: Oyeron. Headquarters. Recuperado de

http://www.mpiweb.org/Libraries/Press/VirtualMeetings.pdf

Fuente, C (2000). Protocolo (5). Oviedo : Nobel.

(2004). Técnicas de Organización de Actos. Madrid: Ediciones Protocolo.

(2005). Protocolo Oficial: Las instituciones españolas del Estado y su ceremonial (1 ${ }^{a}$ edición) . Madrid: Ediciones Protocolo.

(2006). Manual práctico para la organización de eventos: Técnicas de organización de actos II. Madrid: Ediciones Protocolo.

(2007). Protocolo para eventos. Técnicas de organización de actos I. Madrid: Ediciones Protocolo. 
(2008a). Protocolo Oficial. Las instituciones españolas del Estado y su ceremonial (4a edición). Madrid: Ediciones Protocolo.

(2008b). Ceremonial de ensueño Revista Internacional de Protocolo, 48, 8-25. (2012). Protocolo para vender. En Misiego, F y Ortega, E (Coord.), Cómprame y iVende!. Las 20 píldoras de los maestros del marketing (pp. 17-124). Madrid: Rasche

Fuente, J. L. y Herrero, J.C. (2011). La comunicación en el protocolo. Las redes sociales, Internet y los medios tradicionales en la organización de eventos. Madrid: Ediciones Protocolo.

Galmés, M-A. (2011). La organización de eventos como herramienta de comunicación de márketing. Modelo integrado y experiencial. Tesis doctoral dirigida por Juan salvador Victoria Más. Facultad de Comunicación. Universidad de Málaga.

Getz, D. (1990). Festival, special events, and tourism. New York: Van Nostrand Reinhold

(1991a). Special Events-Managing Tourism. Oxford: Butterworth \& Heinemann. (1991b). Festivals, special events, and tourism. New York: Van Nostrand Reinhold. (1997). Event Management \& Event Tourism. Oxford: Cognizant Communication Corporation.

(1999). The impacts of mega events on tourism: Strategies for destinations. En Andersson, T. D., C. Persson, B. Sahlberg, \& L. Strom, (Ed.). The Impact of Mega Events. (pp.5-32). Ostersund, Sweden: European Tourism Research Institute.

(2007). Events Studies. Theory, research and policy for planned events. Oxford: Elservier Ltd.

Girginov, V. y Parry, J (2005). The Olympic Games Explained: A Student Guide To The Evolution Of The Modern Olympic Games. New York: Routledge.

Gnoth, J. (1997). Tourism and motivation and expectation formation. Annals of Tourism Research, 24(2), 283-304.

Gnoth, J., y Anwar, S. A. (2000). New Zealand bets on event tourism. Cornell Hotel and Restaurant Administration Quarterly, 41 (4), 72-83.

Goldblatt, J. (2005). Special Event: Event Leadership for a New World. (4a ed.). Hoboken: John Wiley \& Sons.

Hall, C. (1992). Hallmark tourist events: Impacts, management, and planning. London: Belhaven.

Hamso, E. (2010). La metodología ROI de planificación de reuniones y eventos. En Ortega, C e Izaguirre, M (eds.), Los eventos: funciones y tendencias (pp. 137170). Bilbao: Universidad de Deusto. 
Hannan, C. (1998) An Introduction to Health and Safety for the Live Music Industry. Morden: Production Services Association.

Hernádez, E. (2011). Documentos del protocolo local. Madrid: El Consultor de los Ayuntamientos (La Ley).

Hernández, S. (2000). El protocolo hoy. Sphera pública: revista de ciencias sociales y de la comunicación, 187-196.

(2006). Los gabinetes de protocolo como herramientas de relaciones públicas en las universidades españolas del siglo XXI. Tesis doctoral dirigida por María Teresa Otero Alvarado. Facultad de Comunicación. Universidad de Sevilla.

Herrero, J. y Campos, G. (2010). El necesario protocolo en la comunicación organizacional. Revista Icono14 (2). Recuperado el 12 de enero de 2011, de http://www.icono14.net

Hiller, H.H. (1998). Assessing the impact of mega-events: a linkage model. Current Issues in Tourism, 1(1), pp. 47-57.

Hinch, T.D. y Higham, J. (2005). Sport, tourism and authenticity. European Sport Management Quartely, 5 (3), pp. 243-256.

Kang, Y. S. Y Perdue, R. (1994). Long-term impact of a mega-event on international tourism to the host country: a conceptual model and the case of the 1988 Seoul Olympics. Journal of International Consumer Marketing, 6 (3/4), 205-25

Lloyd, H y Lloyd, P (1993). Relaciones Públicas. Madrid: Pirámide

López-Nieto, F. (1985). Honores y protocolo. Madrid: El Consultor. (1995). Manual de Protocolo. Barcelona: Ariel.

(1998). La documentación del protocolo. Madrid: Bayer Hermanos.

(1999). Legislación de protocolo. Madrid: Dykinson.

(2000). Honores y protocolo (2) (2a ed.). Madrid: El Consultor.

(2003). Manual de protocolo (4a ed.). Barcelona: Ariel.

Marín, F. (1997). Fundamentos del Protocolo en la Comunicación Institucional. Madrid: Síntesis.

(2000). Protocolo y comunicación. Los medios en los actos públicos. Barcelona: Bayer Hermanos.

(2004a). Diccionario de Comunicación Corporativa e institucional y relaciones públicas. Madrid: Fragua.

(2004b). El protocolo en los actos de empresa. La gestión de eventos corporativos. Madrid: 2004

Martí, D. (2008). Comunicación y Protocolo: perspectivas teóricas. Icono14, Revista de Comunicación y Nuevas Tecnologías, 6, 79-104. Recuperado el 26/5/10 de http://www.icono14.net/revista/num11/141105.pdf 
Martínez, I. (2006). El Protocolo en la administración local. Madrid: Ediciones Protocolo.

Masterman, G. (2004). Strategic sports event management: an international approach. Oxford: Elsevier Buterworf-Heinemann.

Mottard, E. (2010). Estado actual y tendencias del sector de congresos, eventos. En Ortega, C e Izaguirre, M (eds.), Los eventos: funciones y tendencias (pp. 6588). Bilbao: Universidad de Deusto.

Nicholson, R. y Pearce, D. G. (2000). Who goes to events: A comparative analysis of the profile characteristics of visitors to four south island events. Journal of Vacation Marketing, 6, (3), 236-53.

Noguero I Grau, A., (1988). Programación y Técnicas de Relaciones Públicas. Barcelona: ESRP_PPU.

Ortega, C. (2010). Introducción. En Ortega, C. e Izaguirre, M (eds.), Lo eventos: funciones y tendencias (pp. 13-18). Bilbao: Universidad de Deusto.

Otero, M. T. (1997). La estructura del protocolo y las relaciones públicas en el estado de las autonomías. Questiones publicitarias: revista internacional de comunicación y publicidad, (6), 73-86.

(2000a). Teoría y estructura del ceremonial y el protocolo. Sevilla: Mergablum. (2002b): Las funciones del ceremonial y el protocolo en la reputación corporativa. Sphera pública: revista de ciencias sociales y de la comunicación, (2), 135-148.

(2003c). Imagen y comunicación en los actos de toma de posesión, Laurea Hispalis. Revista Internacional de Investigación en Relaciones Públicas, Ceremonial y Protocolo, (2), 203-216.

(2005): Normativa de protocolo en el ámbito de la Junta de Andalucía: régimen de precedencias y tratamientos. Comunicación: Revista Internacional de Comunicación Audiovisual, Publicidad y Estudios Culturales, (3), 187-208.

(2006). Relaciones públicas y gestión de públicos en eventos: los principios rectores del ceremonial y el protocolo. Anàlisi: Quaderns de comunicació i cultura, (34), 255-269, recuperado de

http://www.raco.cat/index.php/Analisi/article/view/55456/64588 el 22/06/2012.

(2009). Protocolo y Organización de Eventos. UOC (Universidad Oberta de Catalunya)

(2011). Protocolo y empresa. El ceremonial corporativo. Barcelona: UOC

Pumar, J. (1990). Guía de Ceremonial y Protocolo (2a ed.). Santiago de Compostela: Caixa Galicia.

Raj, R., Walters, P., Rashid, T. (2008). Events Management: An Integrated and Practical Approach. London: Sage. 
Ralston, L.S., y Hamilton, J.A. (1992a). The application of systematic survey methods at open access special events and festivals. Visions in Leisure and Business, 11(3), 1824.

Ritchie, B. W. y Adair, D (2004). Sport Tourism: Interrelationships, Impacts and Issues. ISBN 1-873150-66-0 (hbk). Clevedon: Brent W. Ritchie,Daryl Adair

Ritchie, J. R. B. (1984). Assessing the Impact of hallmark events: Conceptual and research Issues. Journal of Travel Research, 23, pp. 2-11.

Ritchie, J. R. B., y Lyons, M. M. (1990). Olympulse VI: a post-event assessment of resident reaction to the XV Olympic Winter Games. Journal of Travel Research, 28(3), 14-24.

Ritchie, J.R.B. y Smith, B. (1984). Assessing the Impact of hallmark events:

Conceptual and research Issues. Journal of Travel Research, 23, 2-11

(1991). The impact of a mega-event on host region awareness: a longitudinal study. Journal of Travel Research, 30, 3-10.

Ritchie, J. y Yangzhou, J (1987). The Role and Impact of Mega-Events and Attractions on National and Regional Tour ism: A Conceptual and Methodological Overview, Proceedings of the 37th Congress of AIEST, Calgary, 28, 17-58

Ridley, J. (2008). Health and Safety in Brief. Oxford: Butterworth-Heinemann.

Robinson, P., Wale, D., Dickson, G. (2010). Events Management. CABI: Wallingford

Roche, M. (2000). Mega-events and Modernity: Olympics and Expos in the Growth of Global Culture. London: Routledge.

San Juan, J.C. (2001). Introducción al Protocolo Oficial del Reino de España y de la Unión Europea. Madrid: Unión FENOSA.

San Salvador, R. (2010). Ciudad, eventos, y ferias. En Ortega, C e Izaguirre, M (eds.), Los eventos: funciones y tendencias (pp. 19-36). Bilbao: Universidad de Deusto

Shone, A. and Parry, B. (2001). Successful Event Management. London: Continuum

Sierra, J y Sotelo, J. (2009). El estado actual del protocolo a nivel jurídico y profesional. Icono 14, (11), recuperado de el 14/05/2012, de http://www.icono14.net/revista/num11/141108.pdf

Silvers, J. (2003). Professional Event Coordination. New York: Wiley.

EMBOK. Event Management Body of Knowledge Project. Disponible en www.juliasilvers.com/embok.htm.

(2004). EMBOK. Event Management Body of Knowledge Project. Recuperado el 20 de marzo de 2013 de www.juliasilvers.com/embok.htm. 
Stella, J. (1997). La organización de eventos. La fiesta inolvidable. Buenos Aires.

Sternberg, R.J., y Lubart, T.I. (1997). La creatividad en una cultura conformista. Un desafío a las masas. Barcelona: Paidós

Tassipolius, D (2005). Event management: a profesional and developmental approach ( $2^{\mathrm{a}}$ eds.). Juta and Company Ltd.

Tarlow, P. (2002). Event Risk Management and Safety. New York: Wiley.

Torrents, F (2005). Eventos de empresa. El poder de la comunicación en vivo.

Barcelona: Deusto.

(2010). Eventos de empresa: comunicación empresarial en vivo y en directo. En Ortega, C e Izaguirre, M (eds.), Los eventos: funciones y tendencias (pp. 4164). Bilbao: Universidad de Deusto

Trastany, R (1994). Ceremonial Práctico. Barcelona: Ateneo.

Tum, J., Norton, P., Nevan Wright, J. (2005). Management of Event Operations. Oxford: Butterworth-Heinemann. (Events Series).

Turbau, I (2011). ¿Por dónde empiezo?: Guía práctica para programar, financiar y comunicar eventos culturales. Madrid: Patrimonio (Ariel).

Van der Wagen, L. (2002). Event Management: For Tourism, Cultural, Business and Sporting Events. Melbourne: Hospitality Press.

Vilarrubias, F. A. (1976). Introducción al protocolo y ceremonial en las corporaciones locales. Madrid: Instituto de estudios de la administración local.

(1994). Tratado de protocolo del estado e internacional. Oviedo: Nobel.

(2003). La forma y el ser en el protocolo, ceremonial, heráldica y vexilología.

Oviedo: Universidad de Oviedo.

(2004a). El protocolo en los actos de empresa. La gestión de eventos corporativos. Madrid: Fragua.

Yeoman, I., Robertson, M., Ali-Knight, J., Drummond, S., McMahon-Beattie, U.

\section{Gloria Campos García de Quevedo}

Doctora en Comunicación (UCJC). Licenciada en Periodismo (UCM). Directora General del Instituto Superior de Protocolo y Eventos. Directora adjunta de Revista Protocolo. Profesora de la UCJC y docente en programas de postgrado en distintas universidades (UMP, UCM, UMH). Consultora en organización de eventos, ha desempeñado distintos cargos en dirección de comunicación y relaciones institucionales en diferentes ámbitos de la administración pública y del Estado. Autora de diversas publicaciones relacionadas con la organización de eventos, de las que destacan las siguientes: (2008). Producción de actos. La puesta en escena del protocolo. Madrid. Ediciones Protocolo. IBSN: 978-84-95789-31-0 
(2011). Las artes escénicas, el espacio y su relación con los eventos. En II Congreso Internacional Suppot/Surface. Escultura y paisaje. Valencia. Fundación Cañada Blanch.

(2012). Eventos para comunicar, capítulo 8 en Cómprame y iVende!. Las 20 píldoras de los Maestros del Marketing, Madrid. Editorial Rasche. IBSN: 978--84940257-0-9

Campos, G y Fuente, C (2013). Organización y predicción de los 'actos políticos'. Herrero, J y Romer, M (Coord.). La comunicación en campaña: Dirección de campañas electorales y márketing político. Madrid: Pearsons (En publicación)

\section{Carlos Fuente Lafuente}

Doctor en Comunicación (UCJC). Licenciado en Periodismo (UCM). Es Director del Instituto Universitario de Protocolo en la UCJC, Presidente de la Revista de Protocolo y vicepresidente primero de la Asociación Española de Protocolo. Fue responsable de protocolo de numerosas instituciones públicas y privadas de España. Ha sido Director de Protocolo de los Premios Príncipe de Asturias durante de 32 años. Creador en 1995 de la Escuela Internacional de Protocolo que presidió hasta 2010. Fue creador y primer presidente de la Organización Internacional de Ceremonial y Protocolo.

Autor de numerosos libros, tres de ellos considerados de referencia: "Protocolo para Eventos", "Manual Práctico para la Organización de Eventos" y "Protocolo Oficial", todos ellos publicados por Ediciones Protocolo, editorial que él mismo ha impulsado.

Es Premio Internacional de Protocolo a la mejor Trayectoria Profesional y miembro de la Orden al Mérito Civil. 